\title{
The Influence of Different Performance Level of Fencers on Simple and Choice Reaction Time
}

\section{A influência dos diferentes níveis de desempenho dos esgrimistas no tempo de reação simples e de escolha}

\author{
Štefan Balkó \\ Zbigniev Borysiuk ${ }^{2}$ \\ Jaromír Šimonek ${ }^{3}$
}

\begin{abstract}
In many sport disciplines reaction time plays a key role in the sport performance. It is good to point out for example ball games or fighting sports (fencing, karate etc.). The research is focused on detection of the differences in the simple and choice reaction time during visual stimulation among elite, sub-elite fencers and beginners. For the measurement a Fitrosword device and the SWORD software were used. An additional stimulus was added during measuring which should increase the overall number of stimuli, but shouldn't force fencer to any reaction whatsoever. The results from presented study can be compared with Hicks law. The next focus of the study was to identify the difference in reaction time during two different movement tasks with different complexity movement requirements. The research was built up on a hypothesis that the results will differ among different performance groups of fencers. The difference however was overt among beginners and elite fencers $(p=0.0088, d=0.5)$ in reaction time during different movement tasks (direct hit vs. lunge). The results of this research could be useful to trainers for training process organisation and increase the effectivity of muscle coordination during several movements in fencing.
\end{abstract}

Key words: Fencing; Visual Stimulus; Reaction time; Additional Stimulus; Hicks law.

Resumo - Em muitos desportos, o tempo de reação desempenha um papel crucial no resultado desportivo. Como exemplo, pode-se citar jogos que envolvam bola ou desportos de combate (esgrima, karate, etc). A pesquisa foca-se na detecção das diferenças entre os tempos de reação simples e de escolha durante os estimulos visuais entre esgrimistas de elite, sub-elite e iniciantes. Para a medição foram usados um aparelho de Fitrosword e o software SWORD. Foi ainda adicionado um estímulo extra durante as medições que leva em consideração o número total de estímulos, sem, no entanto, forçar o esgrimista a esboçar qualquer reação. Os resultados deste estudo podem ser comparados com a lei de Hicks. O próximo objetivo do estudo foi identificar a diferença no tempo de reação entre duas tarefas de movimento diferentes com diferentes exigências no tipo de complexidade motora. A investigação foi formulada sobre a hipótese de que os resultados irão divergir entre os diferentes grupos de esgrimistas. A diferença $(p=0.0088, d=0.5)$ foi evidente entre os iniciantes e os de elite no tempo de reação durante as diferentes tarefas motoras (golpe directo vs. ataque). Os resultados desta investigação poderão ser úteis para os treinadores no seu esquema de treinos e aumentar a eficácia da coordenação muscular durante os vários movimentos na esgrima.

Palavras-chave: Esgrima; Estímulo Visual; Tempo de reação; Estímulo Adicional; Lei de Hick.
1 Faculty of Education. J. E. Purkyne University in Ústí nad Labem. Czech Republic.

2 Faculty of Physical Education and Physiotherapy. Opole University of Technology. Poland.

3 Faculty of Education. Constantine the Philosopher University in Nitra. Slovak Republic.

Received: 26 April 2016 Accepted: 04 July 2016 


\section{INTRODUCTION}

Thanks to the training process and characteristic movement activity during a fencing match, fencing can be therefore considered as a sport discipline in which reaction time plays a significant role for the sport performance ${ }^{1}$. Fast reaction, which is closely related to the visual or tactile stimuli processing, muscle coordination during the movement, technical and tactical abilities or optimal mental state represent the elementary determinants influencing the overall performance in fencing. During training or match, fencers are quite often exposed to situations, in which they have to decide to which stimulus (e.g. visual, tactile) they should react to first and which to ignore. The reaction has to be as fast as possible because otherwise any delay in the response on a stimulus can negatively turn the tide of the match. The significance of the reaction time in fencing has been examined by many specialists including ${ }^{1-4}$. Schmidt and Wrisberg ${ }^{5}$ note, that elite athletes have the ability to better perceive sensory information if they have more experience gained by training. Czajkowski ${ }^{1}$ noticed the differences during complex information processing. Less experienced athletes have significantly slower information processing speed opposite to the more experienced athletes. The level of the reaction time (RT) relates also with the information processing speed in central nervous system (CNS). The longest segment of information processing is the identification phase of the stimulus, during this time the information content from the environment is analysed by sensory organs ${ }^{5}$. The causes of RT delay and prolonging can be also related to the complexity of a specific movement or coordination requirements of a certain situation. A significant difference between simple RT (SRT) and RT connected to the movement complexity requirements was found by Mickevičienè et al. ${ }^{6}$. Some researches however didn't find results showing significant differences in RT which were related to any movement complexity requirements ${ }^{7}$. During the movement connected with requirement on complexity, the RT prolongs because the system organisation in order to initiate a move requires more time. The time passed from the stimulus occurrence, perception, signal transmitting to CNS, decision making, signal transition to specific muscles and movement initiation takes around $50-300 \mathrm{~ms}$. This time delay between stimulus exposure and movement initiation is also caused by so called receptor intake delay and the fire of the neuron between fibres also takes significant portion of the time. The passage of the signal between neural pathways and CNS is therefore prolonged. The level of RT is therefore mostly influenced in these parts of the nervous system. The SRT values of athletes vary between $0.24-0.10$ second faster than among normal population. Barcelos et al. ${ }^{8}$ however stated that among longer training individuals without long-term sport experience a significant difference of SRT was detected. These findings correlates with the results of Kida et al. ${ }^{9}$ who also confirmed a significant difference in SRT between elite baseball players and a group of beginners. These conclusions support the assumption that in these sports 
the level of SRT is not the main predictor of a successful performance. Fontani et al. ${ }^{10}$ add that thanks to years of experience gained by training process, professional athletes have lower values if choice reaction time (CRT). The phenomenon of CRT is tied to the Hicks law. Validity of this law, which he describes the relationship between CRT and logarithm of stimuli number which is linear, was proved by many researchers e.g. Jensen $^{11}$ or Gignac and Vernon ${ }^{12}$. These authors found out that the RT is proportional to the number of processed stimuli.

The development of speed reaction is very complicated and has longer duration and corresponds with specific movement requirements of a selected sport discipline. The results of the study conducted by Sanderson ${ }^{13}$ shown that the increased number of stimuli gradually increasing from one stimulus to five stimuli the RT among fencers prologues. Williams and Walmsley ${ }^{14}$ observed in their study different RT among different groups of less and more experienced fencers. The results have shown that shorter times were achieved by elite fencers and not by fencers belonging into lower performance category. Borysiuk ${ }^{2,3}$ also found out, that there are differences in RT between experienced fencers and beginners. In his study, more experienced fencers (active fencing in average 8.2 years) had significantly faster RT, than beginners during tactile and visual simulation test. From these results we can assume that visual and tactile simulation can have significance for professional fencing. In relation to the observed groups of fencers this article will also focus on differences between simple and choice reaction time during visual stimulation. The so called additional stimulation was also used during measurements which may increase the number of stimuli; however this stimulation shouldn't force the fencer to perform any movement at all. The results of this work and its findings in the area of choice reaction time analysis can be confronted with Hicks law ${ }^{15,16}$. Finally the research will observe the differences between reaction time of two movement tasks connected with different requirements on complexity of the movement. This work is based on the premise that it will find out significant differences between fencers of various experience level.

\section{METHODOLOGICAL PROCEDURES}

\section{Participants}

The research sample consisted of 43 fencers (epeists, male) in the ages of 22.7 years (+/- 6.4). Fencers were divided based on their current performance levels into three specific groups. First group A consisted of 14 elite fencers of average age 29.9 years (+/ 6.2) who have been active fencers for at least 14.9 years (+/- 5.9). These fencers are participating in National Championships even in International Championships and World Cups and Olympic Games. In the next group B there were fencers belonging to the second performance level of the Czech fencing federation ranking (except for the first $20 \%$ fencers in Czech rankings). Group C consisted of 14 beginner participants of the average age of 21.3 years (+/- 5.7), who 
have been fencing no longer than 1.6 years $(+/-0.7)$. Fencers from this group have no experience with any official competition. All tested groups were introduced with all used methods before the research. All participants agreed to participate and signed an agreement contract which included information about the research.

\section{Procedures}

\section{- Measurement of the simple and choice reaction time}

The following part of this research will be focused on the observation of simple and choice reaction time during visual stimulation with the use of additional stimulus, which although increased the overall amount of stimuli, but wasn't related to any difficult movement task (extension in elbow joint of the armed arm after lighting LEDs for hitting the target). Fencers during on guard position with the epée guard placed on the horizontal obstacle (Figure 1a) had to hit the target after lighting up red or green LED light, direct hit for red LED (Figure 1c), or bounce for green LED (Figure 1b) and then hit the target (Figure 1c). When fencers saw a yellow LED light, they were instructed to do nothing. Reaction on one stimulus (red LED light) corresponded with the simple reaction time (SRT). Reaction on two stimuli (red and green LED light) was labelled as choice reaction time (CRT). For all subjects the same movement distance was established for effective SRT and CRT measurement (distance between the target and horizontal obstacle was $125 \mathrm{~cm}$ ). The middle of the target was placed in a specific height of fencer's xiphisternum, similarly as Williams and Walmsley ${ }^{14}$ used it in their study. In case of CRT2 and CRT3 measurements a sensitive vertical obstacle was placed in half of the previous distance $(62.5 \mathrm{~cm}$ from the target and $62.5 \mathrm{~cm}$ from the horizontal obstacle). Stimuli occurred between 600 - 2000 ms after placing the epée guard on the horizontal obstacle.

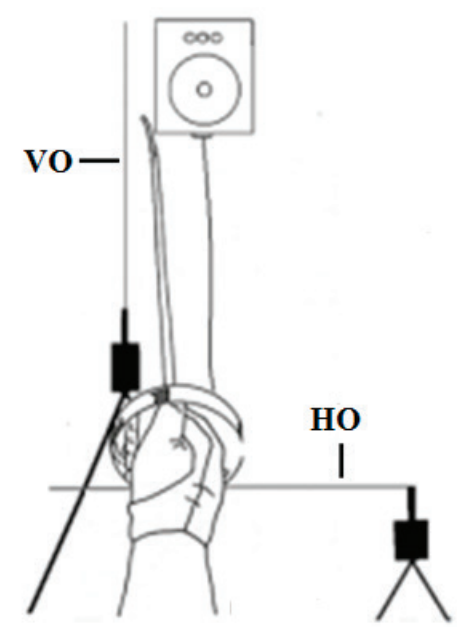

a)

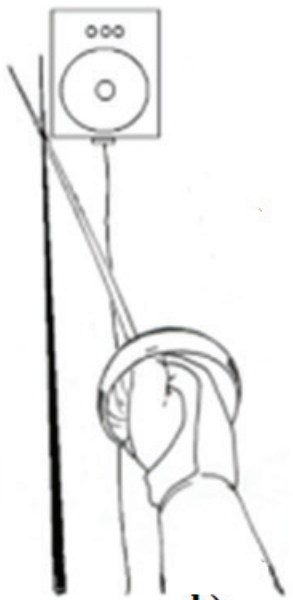

b)

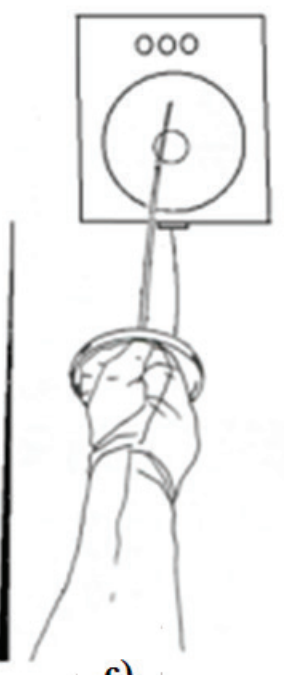

c)

Figure 1. Movement phases during SRT, CRT2 and CRT3 measurement ${ }^{17}$ (modified). V0 = vertical obstacle; $\mathrm{HO}$ = horizontal obstacle. 
In case the red LED diode lightened up, when fencers had to perform only a direct hit, the diode lighted up 20 times during this process. This protocol was the same for all test subjects. During the CRT2 measurement 10 stimuli were generated for a direct hit (red LED light) and 10 stimuli for bounce (green LED light). The time interval of the stimuli occurrence was the same as in the previous case $(600-2000 \mathrm{~ms})$. In case of CRT3 red LED stimulus occurred 10 times, green LED occured also 10 times and yellow additional LED stimuli occurred 7 times.

Based on the suggestion made by Tanaka et al. ${ }^{18}$, all values over 1000 $\mathrm{ms}$ during the simple reaction time measuring were discarded, as well as all the values under $100 \mathrm{~ms}$ which were according to Iida et al. ${ }^{19}$ valued as anticipation values. All values under $160 \mathrm{~ms}$ within CRT2 and CRT3 were discarded and marked as anticipatory, values and measurement above $2000 \mathrm{~ms}$ were marked as errors, similarly as in other research ${ }^{20-22}$. First 15 correct attempts of SRT, CRT2 and CRT3 were used for further analysis (after exclusion of failed or anticipatory attempts).

\section{- Measurement of RT during different movement tasks}

In this part of the research the test subjects had to perform 20 lunges from the on guard position after LED light was lighted up (Figure 2a) and hit the target (Figure $2 \mathrm{~b}$ ). The lunge reaction time (LRT) was also analysed and measured form the initiation of the red LED diode as in the case of measurement of SRT. In order to eliminate any interference of the results by the interindividual height differences of the test subjects a method from the study of Williams and Walmsley ${ }^{14,23}$ was used. As well as in the previously mentioned study, the height of the test subject was multiplied by a specific coefficient. The movement distance (Figure 2a) was established from the intersection of the vertical obstacle facing down perpendicular from the centre of the target. From this place on the pad to the target the distance was measured according to a specific coefficient (height in $\mathrm{cm}$ multiplied by 1.5). The leg on the rear side (also inner side from the fencer's shoe) must not exceed the mark before the stimulus occurred and so the fencers had to stay still behind it. The centre of the target was placed in the height opposite fencer's xiphisternum while standing up. Based on the stimuli occurrence the test subjects had to act as fast as possible and lunge from a specific distance. Angle in elbow joint was always at approximately 90 degrees. The lunge reaction time (LRT) was compared with simple reaction time (SRT) detected in on guard position where subjects had to perform the extension in the elbow joint for hitting the target. This protocol was the same for all test subjects, therefore it was important to ensure that no test subject observed the measurement process. Test subjects were instructed to perform all tasks in maximum possible speed.

\section{Data analysis}

SWORD software was used for the analysis of the levels of RT (SRT, CRT2, and CRT3). Data extracted were then recorded and exported into Microsoft Excel 2010 for further processing. After discarding the anticipa- 

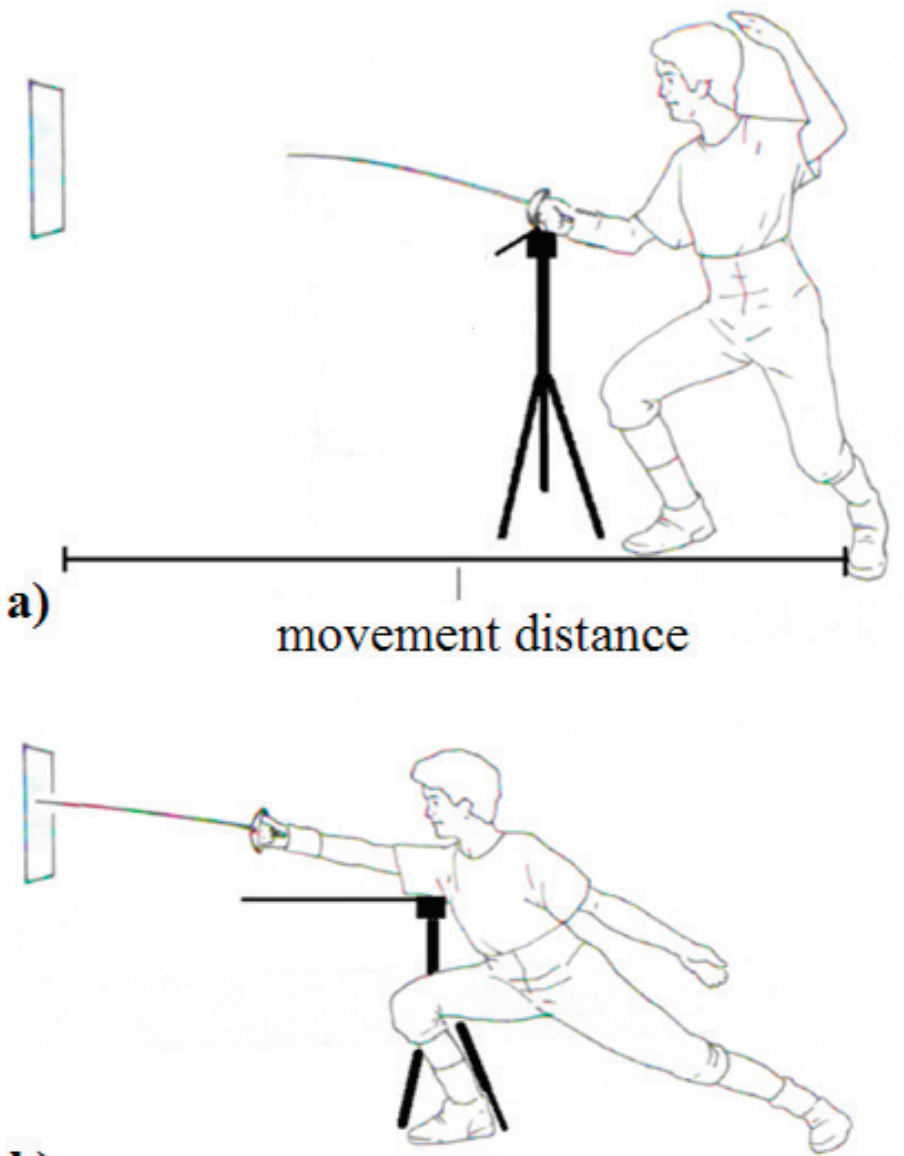

b)

Figure 2. The movement from on guard position to the lunge ${ }^{17}$ (modified).

tory and fail attempts arithmetic mean, median and standard deviation were calculated. The same procedure was followed for calculating the values of the lunge reaction time (LRT). For the purposes of statistical processing, Statistica 6.1 software and Microsoft Excel 2010 were used. Based on the normality test (Shapiro Wilks W test) it was found that data have to be considered as not parametrical. For median equality testing Kruskal-Wallis test was used for all observed groups of participants if statistically significant difference was found between all three groups. For detecting differences between two groups (A vs. B, A vs. C, B vs. C) Mann-Whitney U test was used. Statistically significant differences were established for $p<0.05$.

\section{RESULTS}

The following part of the analysis was focused on the difference spotting during reaction time of the fencers in on guard position, during which the fencers had to react in a specific way when a LED light lighted up.

Figure 3 shows that the beginners reacted most slowly to the visual stimuli ( 1 - 3 stimuli). We can also observe that the increase in the number of stimuli had no influence on the RT difference between the groups A and $\mathrm{B}-$ their time values were almost equal. 


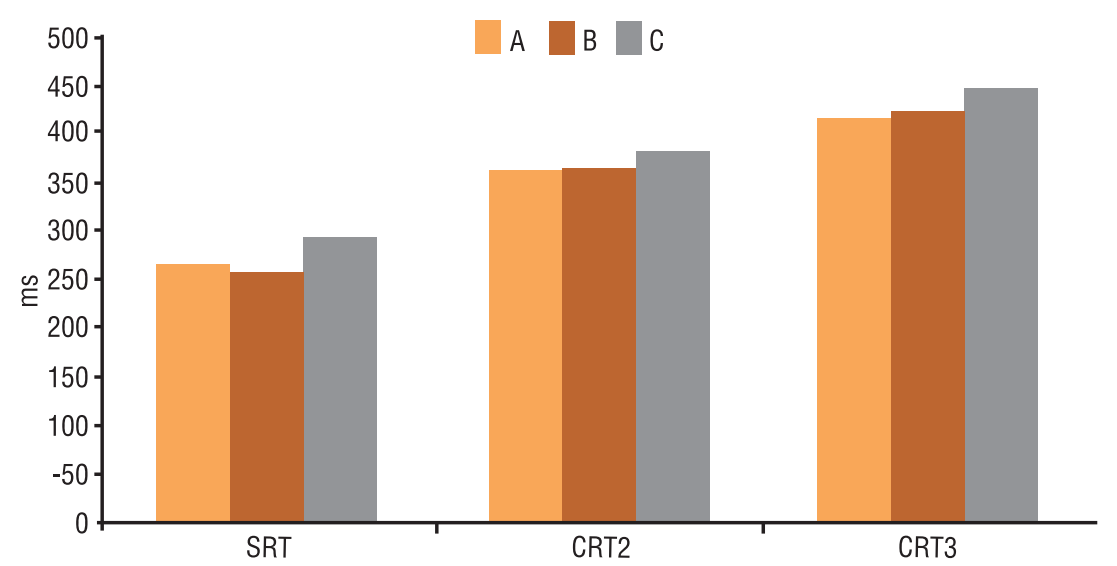

Figure 3. Differences between groups in RT.

A, B, C = tested groups; SRT = simple reaction time; $C R T 2$ = choice reaction time (2 stimuli); CRT3 $=$ choice reaction time with additional stimulus (3 stimuli).

Table 1. Differences of RT among groups $A, B$ and $C$.

\begin{tabular}{lccccc}
\hline Group & $\mathrm{n}$ & $\mathrm{SRT}(\mathrm{Me})$ & CRT2(Me) & CRT3(Me) & LRT vs. SRT(Me) \\
\hline A & 14 & 262.5 & 360.5 & 416.5 & 18.5 \\
B & 15 & 258 & 364 & 424 & 34 \\
C & 14 & 292 & 381.5 & 447.5 & 61.5 \\
H & & 2.92 & 0.69 & 3.15 & 6.54 \\
p & & 0.2328 & 0.7077 & 0.2075 & 0.0381 \\
ES & & 0.07 & 0.02 & 0.08 & 0.16 \\
\hline
\end{tabular}

$\mathrm{H}=$ value of Kruskal-Wallis test; $\mathrm{p}=\mathrm{p}$ level; $\mathrm{ES}=$ effect size $(\eta 2) ; \operatorname{SRT}(\mathrm{Me})=$ simple $\mathrm{RT}$ (1 stimulus, median); CRT2(Me) = choice RT (2 stimuli, median); CRT3(Me) = choice RT (3 stimuli, median); LRT vs. SRT(Me) = difference between LRT and SRT (median).

Kruskal-Wallis test results shown that any significant differences in RT values among all observed groups of fencers (SRT, CRT2, and CRT3) were not discovered. It is therefore not possible to confirm whether the additional stimulus had any influence on fencers with different experience level. Kruskal-Wallis test has discovered a significant difference $(p=0.0381$, $\eta 2=0.16)$ between LRT and SRT among observed fencers. Based on these findings we used Mann-Whitney U test to compare each group with each other. The relation of LRT and SRT is analysed in order to verify the influence of different movement task on the reaction time of fencers who have different experience level. Detailed characterisation of the differences between LRT and SRT is described within the lower graph (Figure 4).

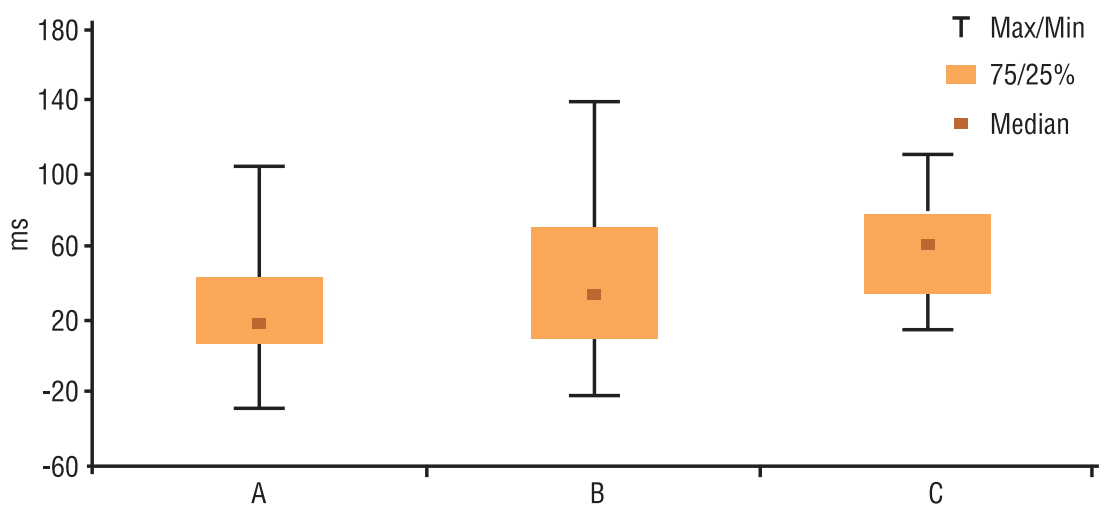

Figure 4. Differences between LRT and SRT among tested groups A, B and C.

Min $=$ minimal value; Max $=$ maximal value; $25 \%=$ lower quartile; $75 \%=$ upper quartile. 
Figure 4 describes differences between all groups of fencers during different movement task analysis. The evened values are between groups $\mathrm{A}$ and $\mathrm{B}$ - opposing the group $\mathrm{C}$, where the difference was most significant.

With the help of Mann-Whitney $U$ test, a significant difference in LRT and SRT values was discovered only between groups A vs. C ( $p=$ $0.0088, d=0.5$ ).

\section{DISCUSSION}

The analysis was trying to verify the influence of stimuli on the RT and also the influence of movement complexity on the levels of RT. According to Hicks law ${ }^{15,16}$ linear increase of RT rises with increasing number of generated stimuli. The existence of this relationship was successfully tested $^{12,13}$. The main hypothesis was that the elite fencers will process the additional stimulus (CRT3) similarly as the effect during two stimuli simultaneously (CRT2), fencers from the other groups will probably process the additional stimulus as a third, separate one (CRT3), which will eventually increase the value of the choice RT. Unlike the usual measuring of the RT where a test subject reacts on visual stimuli by pressing a specific button with a finger, device in our study simulated real conditions: fencers in on guard position react through extension of the armed arm for hitting of the target. The fact, that there is not any significant difference in SRT among fencers visible was quite expected. SRT is very strongly genetically conditioned and it is very difficult to influence it by training, similar findings were made by Sergienko ${ }^{24}$. This was also supported by researches concerning simple reaction time among sport active and inactive population analyzed by several researchers ${ }^{8,9}$ unfortunately no significant difference was found among the values of RT between observed groups. This research came up with similar findings. No significant difference was found out between groups A, B and C in the values of SRT $\left(p=0.2328, \eta^{2}=0.07\right)$. These findings are in contrast with results of Borysiuk $\mathrm{k}^{2,3}$ and also Tyshler and Tyshler ${ }^{25}$ who inform about the fact: more experienced fencers have faster RT than beginners. It is necessary to point out that these findings were conducted via different measuring device and test subjects reacted sitting down and again, just reacting by pressing a button on a reaction time identifier. This study hasn't found any significant difference among groups of fencers in CRT2 results $\left(p=0.7077, \eta^{2}=0.02\right)$, not even in CRT3 ( $p$ $=0.2075, \eta^{2}=0.08$ ). Given results however support the validity of Hicks law in all three groups of fencers (with the increasing number of stimuli the RT levels also increased). This conclusion is however in contradiction with the hypothesis that the additional stimulus will not have any significant influence on fencers RT increase. Similar findings supporting this theory were made by Gutierrez-Davila et al. ${ }^{26}$. Their study shows that not even the difference in choice RT (CRT) among elite and sub-elite fencers was found out. It is also necessary to note that the suggestions that more experienced athletes have lower levels of RT cannot be proven ${ }^{5,10}$. 
Even though there hasn't been any significant difference in the RT value found during the on guard position, it was possible to expect that a difference could be found during different movement task connected to another movement and coordination requirement. Differences among the three groups of fencers in muscle coordination during the fencing lunge were found in the study of Balkó et al. ${ }^{27}$. The importance of coordination abilities in sports and their development is stressed by Šmonek ${ }^{28}$. The hypothesis that the requirements connected with muscle coordination would increase the levels of RT was verified. Between the groups A and C the significant difference in RT before lunge (LRT) and reaction time in on guard position before hitting the target (SRT) was detected $(p=0.0088$, $d=0.5$ ). Between the groups $\mathrm{A}$ vs $\mathrm{B}$ and $\mathrm{B}$ vs $\mathrm{C}$ no significant difference was found. It is possible to conclude, that in elite fencers any increase of movement requirement doesn't significantly influenced their RT, however beginners showed significant changes and differences in RT when the complex of subsequent movement was given.

\section{CONCLUSION}

Fencers are exposed to a variety of stimuli (mainly visual and tactile) during their training or matches in tournaments which means that fencing can be considered as sport discipline in which the reaction time is significantly taking part in overall speed of offensive and defensive actions and reaction time. During a match, the fencer has to decide very quickly to which movement he/she has to react and which to ignore. Based on the results it cannot be simply concluded on the importance of simple and reaction time in fencing. A significant difference between the reaction time during lunge and reaction time associated with easier movement requirements in on guard position was detected. These findings can be related with the fact that the experience of elite fencers improves their movement effectivity. The results of this article can be used for sport preparation during training process with the emphasis on reaction time and muscle coordination during lunge development. It is important to note that the results of this analysis have to be taken with discretion mainly because the overall fencing performance consists of many factors which cannot be downgraded. It can be assumed that during the measurement of reaction time on desktop reaction time identifier different results could be found in comparison with the results in the presented study. Similarly, the results could be different with more tested subjects in observed groups.

\section{REFERENCES}

1. Czajkowski Z. Understanding Fencing: the unity and practise. Staten Island, NY: SKA Swordplay Books; 2005.

2. Borysiuk Z. Psychomotor reactions in fencing dependence of stimuli type. Rev Bras Cineantropom Desempenho Hum 2008;10(3):223-229.

3. Borysiuk $Z$. The signifikance of sensorimotor response components and EMG signals depending on stimuli type in fencing. Acta Universitatis Palackianae Olomucensis Gymnica 2008;38(1):43-54. 
4. Harmenberg J, Ceci R, Barvestad P, Hjerpe K, Nyström J. Comparison of different tests of fencing performance. Int J Sports Med 1991;12(6):573-576.

5. Schmidt RA, Wrisberg CA. Motor learning and performance: A situation-based learning approach. 4th ed. Champaign: Human Kinetics; 2008.

6. Mickevičienė D, Motiejūnaitė K, Skurvydas A, Darbutas T, Karanauskienė D. How do reaction time and movement speed depend on the complexity of the task? Sportas 2008;69(2):57-62.

7. Shen YCh, Franz EA. Hemispheric competition in left-handers on bimanual reaction time tasks. J Motor Behav 2005;37(1):3-9.

8. Barcelos JL, Morales PA, Maciel, RN, Azevedo MMA, Silva VF. Time of practise: a comparative study of the motor reaction time among volleyball players. Fitness Perf J 2009;8(2):103-109.

9. Kida N, Oda S, Matsumura M. Intensive baseball practise improves the Go/ Nogo reaction time, but not the simple reaction time. Cognitive Brain Res 2005;22(2):20-27.

10. Fontani G, Lodi L, Felici A, Migliorini S, Corradeschi F. Attention in athletes of high and low experience engaged in different open sklil sports. Percept Motor Skill 2006;80(4):308-317.

11. Jensen A. The G factor: The science of mental ability. Westport: Praeger; 1998.

12. Gignac GE, Vernon PA. Reaction time and the dominant and non-dominant hands: An extension of Hick's Law. Pers Indiv Differ 2004;36(3):733-739.

13. Sanderson FH. The effect of directional uncertainty on reaction time and movement time in a fencing task. J Sport Sci 1983;1(2):105-110.

14. Williams LRT, Walmsley A. Response amendment in fencing: differences between elite and novice subjects. Percept Motor Skill 2000;91(1):131-142.

15. Hick WE. On the rate of gain of information. QJ Exp Psychol 1952;4(1):11-26.

16. Hyman R. Stimulus information as a determinant of reaction time. J Exp Psychol 1953;45(3):188-196.

17. Cheris E. Fencing. Step to Success. Champaign: Human Kinetics; 2002.

18. Tanaka K, Hasegawa M, Kataoka T, Katz L. The effect of self-position and posture information on reaction time. Int J Comput Sci Sport 2010;9(3):4-14.

19. Iida Y, Miyazaki M, Uchida S. Developmental changes in cognitive reaction time of children aged 6-12 years. Eur J Sport Sci 2010;10(3):151-158.

20. Arcelin R, Delignieres D, Brisswalter J. Selective effects of physical exercise on choice reaction processes. Percept Motor Sklill 1998;87(1):175-185.

21. Davranche K, Audiffren M, Denjean A. A distributional analysis of the effect of physical exercise on a choice reaction time task. J Sport Sci 2006;24(3):323-329.

22. Deligniéres D, Brisswalter J, Legros P. Influence of physical exercise on choice reaction time in sport experts: the mediating role of resource allocation. J Hum Movement Stud 1994;27(1):173-188.

23. Williams LRT, Walmsley A. Response timing and muscular coordination in fencing: A comparison of elite and novice fencers. J Sci Med Sport 2000b;3(4):460-475.

24. Sergienko L. Genetische grenzen sportlicher lestungen. Lesstungsport 2000;30(1):39-42.

25. Tyshler D, Tyshler G. Fencing. Moscow: Physical Education and Science Press; 1995.

26. Gutierrez-Davila M, Rojas FJ, Antonio R, Navarro E. Response timing in the lunge and target change in elite versus medium-level fencers. Eur J Sport Sci 2013;13(4):364-371.

27. Balkó Š, Borysiuk Z, Balkó I, Špulák D. The influence of different performance level of fencers on muscular coordination and reaction time during the fencing lunge. Arch Budo 2016;12(1):49-59.

28. Šimonek, J. Coordination Abilities in Volleyball. 1st ed. Warszaw/Berlin: DeGruyter; 2014.

\section{CORRESPONDING AUTHOR}

Štefan Balkó

J. E. Purkyne University in Ústí nad Labem, Czech Republic Ceské mládeže 8, Ústí nad Labem, 40096, Czech Republic E-mail: stefan.balko@ujep.cz 